\title{
Hydro Matrix Power Wheels Generate More than 5 GW/h from Main Branch Canals (River Nile) in Egypt
}

\author{
Hesham F. A. Hamed', Ahmed M. Kassem², Medhat E. M. Ali² \\ ${ }^{1}$ Faculty of Engineering, Elminia University, Minya, Egypt \\ ${ }^{2}$ Faculty of Engineering, Sohag University, Sohag, Egypt \\ Email: HFAH661@yahoo.com, kassemahmed53@hotmail.com, en.med_kad@yahoo.com
}

Received 16 December 2015; accepted 28 March 2016; published 31 March 2016

Copyright (C) 2016 by authors and Scientific Research Publishing Inc.

This work is licensed under the Creative Commons Attribution International License (CC BY). http://creativecommons.org/licenses/by/4.0/

cC) (i) Open Access

\begin{abstract}
In this paper, a new hydromatrix power wheels generation unit is presented. This presented hydromatrix power unit is aimed to convert the water movement in the main river branches into electrical power. It is found that the generated power based on the proposed hydromatrix power can be generated about $5 \mathrm{GW} / \mathrm{h}$ in Egypt. The proposed hydromatrix power unit based on the under shot water wheel type and the generated electrical power using this proposed unit is calculated at head; difference equal to 1 meter is presented.
\end{abstract}

\section{Keywords}

Hydromatrix Scheme, Electrical Energy, Development, Electricity, Renewable Energy, Project Financing, Egypt

\section{Introduction}

Hydropower is a renewable energy source most widely used all around the world [1], but with very low gear head (VLH) differences between 0.5 and $2.5 \mathrm{~m}$. The operation of water supply system already exists. So there will be no extra operation cost. The annual maintenance cost is estimated to be $1 \%$ investment cost of hydropower plant [2]. Renewable energy from small-scale hydro, modern biomass, wind, solar, geotherm and biofuels accounted for $2.7 \%$ of global final energy consumption in 2008 and is growing very rapidly [3]. Small hydro systems using turbines/wheels can be used to convert mechanical energy from water flow into electricity [4].

Egypt is the largest oil and natural gas consumer in Africa, accounting for more than $20 \%$ of total oil con- 
sumption and more than $40 \%$ of total dry natural gas consumption in Africa in 2013, based on data from the 2014 BP Statistical Review. The rapid growth of oil and natural gas consumption over the past few decades has been driven by increased industrial output, economic growth, energy-intensive gas and oil extraction projects, population growth, an increase in private and commercial vehicle sales, and energy subsidies [5] [6]. This country generated almost 152 billion kilowatt-hours (KWh) of electricity in 2012, of which about 70\% was fueled by natural gas, $20 \%$ from oil, and $10 \%$ from renewable, mostly hydropower generation by high dam in Asswan.

Egyptian Empire struggles with natural gas shortages, particularly during the summertime months and typically imports fuel oil and diesel to covering the deficit. Rising power demand, natural gas supply shortages, ageing infrastructure, and inadequate generation and transmission system capacity have led to frequent blackouts in Egypt.

\section{Requirements for Hydromatrix}

Hydropower with VLH differences has been utilized for some centuries, for several reasons:

- The building of dams for low heading differences is simpler and less costly than larger dams.

- Mechanical superpower was very valuable, and even small head drops were therefore economical.

- The exploitation of the natural flow of water to get on the movement of turbines.

VLH hydropower has become attractive again with some new developments have appeared, whereby the increasing ecological consciousness has meant that focus not just on power output and cost effectiveness, but also on ecological performance.

\subsection{Proposed Hydromatrix Water Wheel}

In this study, a small hydromatrix model is designed using sum pieces of wood. This small model consists of some small under shot water wheels mounted in special slots as show in Figure 1. The speed of the water wheel depends on the stream water speed, and the stream water speed depends on the water head and the cross section area of the canal.

\subsection{Prototype Operating in Irrigation Channel}

Simple prototype from wood to lustrate the new hydromatrix water wheel is designed from wood and we put it in small irrigation channel as shown in Figure 2. This prototype is used the under shot water wheel to obtain the power from natural water flow without dam building. We just make some change on the channel width by dividing it to slots for width equal to one third to the natural width of the channel. By changing the width of the channel to one third the water speed will be increased to triple natural velocity and this will increase the velocity of the turbine.

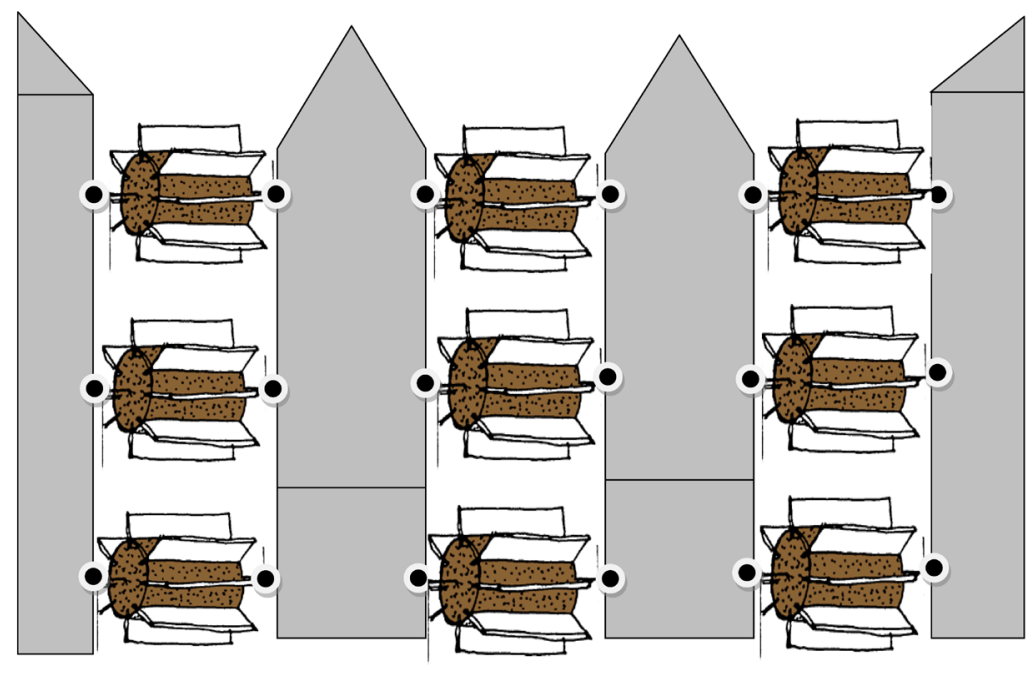

Figure 1. Hydromatrix power water wheel model. 


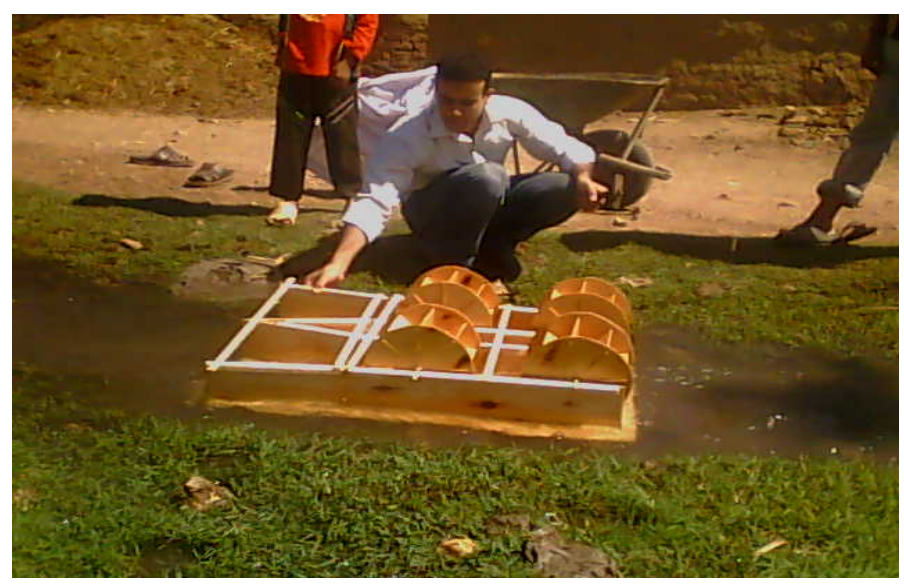

Figure 2. Prototype for hydromatrix in irrigation channel.

\section{Power Determination from Each Slot}

Let's say for example that we have a natural channel width equal to 12 meters and 2 meters in depth so we design our model as the width of slot is equal to 4 meters and the depth is equal to 2 meters for changing the overall channel width one third. For natural velocity equal to 1.5 meter/sec of the channel before modified we have the velocity in our mode slot equal to 4.5 meters/sec so we have a flow rate of 36 cubic meters per second with a head of 1 metres. The power formula given below

$\mathrm{p}=\eta \mathrm{QHg} \rho \mathrm{W}$ where

$\mathrm{P}=$ the Total Available Power

$\mathrm{g}=$ acceleration due to gravity $=9.81 \mathrm{~m} \cdot \mathrm{s}^{-2}$

$\mathrm{H}=$ head $(\mathrm{m})=1 \mathrm{~m}$ and $\mathrm{Q}=$ flow $\left(\mathrm{m}^{3} / \mathrm{s}\right)=\mathrm{A} * \mathrm{~V}=4 * 2 * 4.5=36 \mathrm{~m}^{3} / \mathrm{s}$

$\rho=$ density of water $=1000 \mathrm{~kg} \cdot \mathrm{m}^{-3}$

$\eta=$ the efficiency due to the losses of civil work and friction due to flow velocity

$\mathrm{p}=36 \times 1 \times 9.81 \times 0.9 \times 1000=317 \mathrm{KW}$ form water flow in only one slot of the new model.

\section{What Turbine Type Can Be Used in Our Hydromatrix}

\subsection{The Impulse Wheel}

One of the earliest hydro tycoon machine for the usage of VLH differences is the caprice wheel. Water is accelerated through a drop, and the fast supercritical flow movement the wheel. Public figure single appearance such a wheel with a $5.20 \mathrm{~m}$ diameter, a width of $4 \mathrm{~m}$, a water depth of $1.5 \mathrm{~m}$, a flow speed of 6-sevener $\mathrm{m} / \mathrm{s}$ and a power production of $141 \mathrm{~kW}$. A theoretical analysis shows that $40 \%$ is the level best possible efficiency. Tests conducted at the Technical University Berlin indicated efficiencies of 35\% - 38\% (Figure 3) [7]. Possible efficiencies therefore range from $35 \%$ to $40 \%$ for specific flow rates of $\mathrm{Q}=1-3 \mathrm{~m} / \mathrm{s}$ per $1 \mathrm{~m}$ width and brain differences (or drops) of $0.4-1.5 \mathrm{~m}$.

\subsection{The Poncelet Wheel}

The Poncelet steering bicycle was developed in France in the 1820s in order to improve the efficiency of undershot roulette rack for VLH differences, and subsequently found widespread application. It consists of a wheel with deep curved blades and an influx with an undershot weir. The water jet from the weir enters the wheel, central its impulse, the water rises interior the wheel and then falls out, performing additional work. Theoretical analysis and experiment conducted by the inventor showed efficiencies of 55\% - 65\%, whereby the efficiency reduces with increasing head difference. Head word differences utilized ranged from 0.75 to approximately 1.7 $\mathrm{m}$, and efficiencies were assumed as sixty to $65 \%$ for head differences between $0.75 \mathrm{~m}$ to $1.2 \mathrm{~m}$, and $55 \%$ - $60 \%$ for head differences between 1.2 and $1.7 \mathrm{~m}$. As Poncelet's second Energy Hydropower converters with head differences below $2.5 \mathrm{~m}$ series of tests did not really confirm the higher efficiency of 65\%, a maximum mechanical efficiency of $60 \%$ is usually assumed (e.g. Müller, 1899). Flow rates ranged from Q $=0.3$ to $1.5 \mathrm{~m}^{3} / \mathrm{s}$ and $\mathrm{m}$ 
Impulse Turbine

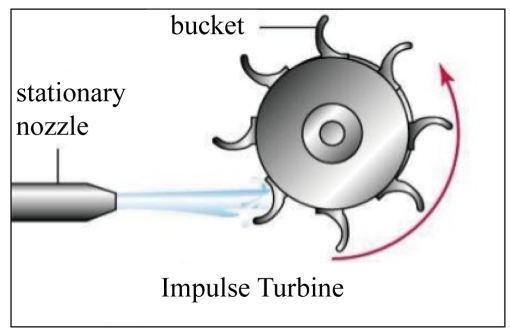

Figure 3. Impulse wheel.

width, with power outputs of $\mathrm{P}=1$ to $13.8 \mathrm{~kW} / \mathrm{m}$ width. Typical diameters were 3 - $6 \mathrm{~m}$ (Poncelet, 1827; Weisbach, 1883). Figure 4 appears a side elevation of a typical Poncelet wheel.

\subsection{The Zuppinger Wheel for VLH Differences}

Zuppinger water cycles were developed for low gear head hydro major power web site with head difference s between 1.5 and $2.5 \mathrm{~m}$, and with power military rating between 5 and 100 kilowatt. They are characterized by curved vane, large diameters between 4.5 and $7.5 \mathrm{~m}$, and a slow rotational velocity of $4-6 \mathrm{rpm}$. The in menstruation was regulated with a weir, so that the upstream water level and the bicycle speed were kept invariable. In social club to exploit head differences between 0.7 and $1.5 \mathrm{~m}$ a special wheel case was developed that did not have a weir inflow, as shown in Figure 5. The wheel maintains the head difference, which way that the wheel speed becomes a purpose of the flow volume. Efficiencies were given as $70 \%-75 \%$, slightly lower berth than the criterion Zuppinger bicycle. No theory for this type of wheel was, however, developed.

The specific flow volumes stove from 1.0 to $1.2 \mathrm{~m}^{3} / \mathrm{s}$ per $1 \mathrm{~m}$ width with power military rank from 5.3 to 12.8 $\mathrm{kW} /(\mathrm{m}$ width). While standard Zuppinger wheels are still (or rather, again) built, the VLH wheel has, to our knowledge, not seen any recent diligence. In principle, it is similar to the recently developed hydrostatic imperativeness wheel (HPW) (Senior et al., Uhuih 2010). Its disadvantages are the large number of blades (and subsequent costs) and the negative consequence of buoyancy forces of the $50 \mathrm{~mm}$ thick wooden blades, which reduce efficiencies by $6 \%$ - 8\% (Schneider et al., 2009). Advantages are the higher theoretical efficiency as a function of the high number of blades, the perceived fish friendliness (Gerhardt, 1893) and the possibility of sediment exit through.

Experimental judgment is, however, considered necessary to provide reliable data for performance prediction. The aim of these developments was to enable the application of double-regulated turbines also for small hydropower project, as well as to provide more efficient solutions for large run-off-river and tidal power plant. In some of these modern unit concepts, as for example HYDROMATRIX, only simply regulated turbines turbines are implemented when this significant simplification is compensated by the number of installed units (Giesecke and Mosonyi, 2009). However, as has been proved by numerous projects, all aforementioned developments could hardly be feasible in the VLH range below $2.5 \mathrm{~m}$ owing to the specific features and limits of the implemented turbine technology.

\subsection{Hydrostatic Pressure Converters}

The hydrostatic pressure difference can be used for power generation in addition to utilization of currents [7]. Two autos that employment hydrostatic pressure as the driving force for low chief hydropower have been developed recently (Senior et al., 2010). Theoretical work indicated the potency of the construct, and small and large-scale modeling psychometric test showed the possible transition efficiencies. The HPW is a simple body of water supply wheel with radial straight blades, whereby the blades run in a curved bed section and cargo hold the upstream water storey; the wheel also acts as a weir (Figure 6(a)). Efficiencies are a affair of the ratio of the down and upstream water level head difference $\mathrm{d}_{2} / \mathrm{d}_{1}$. Theoretical and experimental efficiencies agreed well and reached from sextuplet $60 \%$ to $90 \%$ for ratios of head difference $d_{2} / d_{1}$ from 0.6 to 0.9 . Initial judgment indicated that the HPW is suitable for head differences between 0.4 and $1.0 \mathrm{~m}$, with flow rate of $0.5-1.5 \mathrm{~m}^{3} / \mathrm{s}$ and m width gift power ratios from 2 to $12 \mathrm{~kW} / \mathrm{m}$ width. The hydrostatic pressure machine (HPM) consists of a hub 


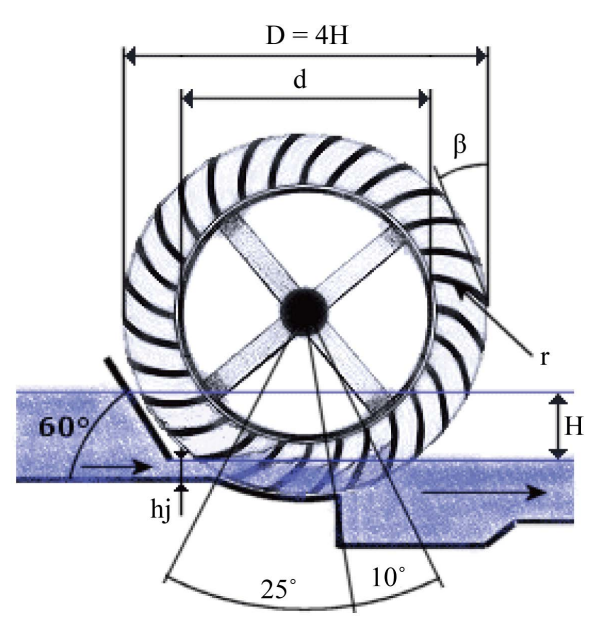

Figure 4. Poncelet wheel.

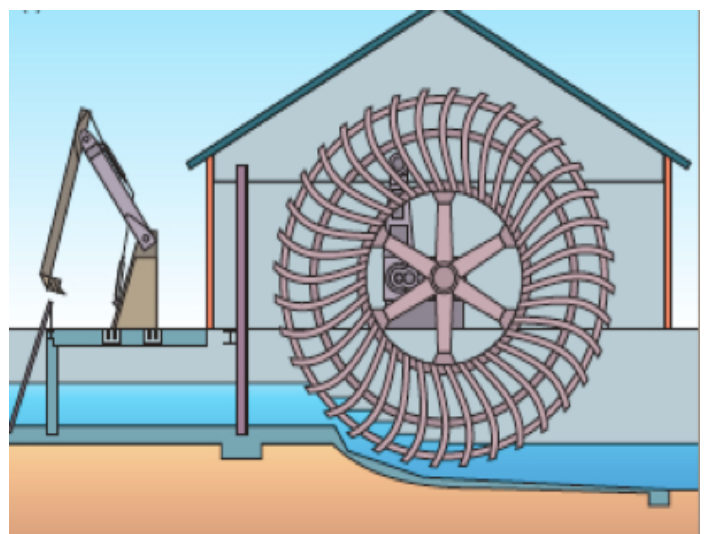

Figure 5. Very low head Zuppinger wheel without regulating inflow weir (Müller, 1899).

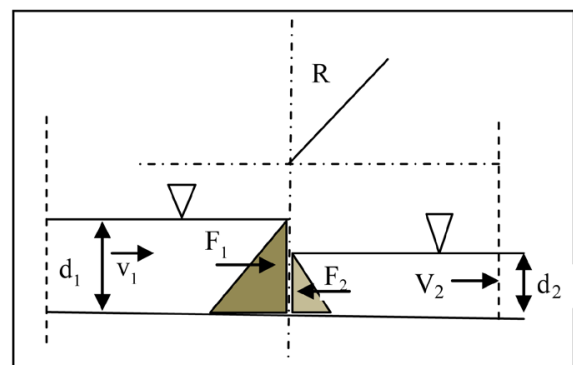

(a)

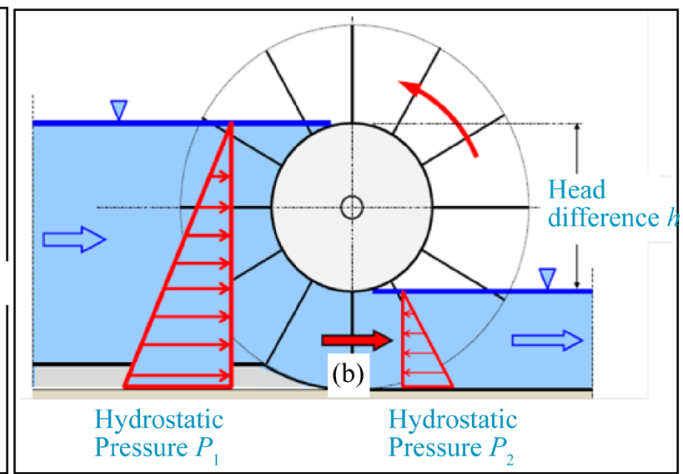

Figure 6. Hydrostatic pressure converters (adapted from Senior et al., 2010). (a) Hydrostatic pressure wheel; (b) Hydrostatic pressure machine.

with a diameter approximately equal to the head difference, and blades that also run in a curved bed section. The upstream water level range the top of the hub, while the downstream level is located at its bottom (Figure 6(b)).

The resulting hydrostatic force acting on the blade drives the machine. Efficiencies are a function of the wheel speed and reduce with increasing speed. In small- and large-scale experiments, efficiencies from $70 \%$ to $82 \%$ were measured for the operational range of speeds (Senior et al., 2010). Head differences range from 1 to $2.5 \mathrm{~m}$, flow rates from 1 to $3 \mathrm{~m}^{3} / \mathrm{s}$ and m width, and power ratings from 7 to $47 \mathrm{~kW} / \mathrm{m}$ width. Recent field measurements indicated overall efficiencies of 0.51 to 0.524 for $Q_{\max }$ from 0.186 to 0.3 cubic meter and mechanical effi- 
ciencies between 0.74 and 0.85 . Both machines are simple and therefore have the potential to be economical; the large cells and continuity of the bed imply improved ecological performance for both fish and sediment passage. Both machines are currently undergoing large-scale/full-scale testing.

\subsection{Design Calculations for (Under-Shot) Low-Head Waterwheels}

\subsubsection{Diameter of Wheel}

When designing an undershot wheel, we must know the "drumhead" since the optimum diameter of the wheel is three to six clip the head. Let's say we measure our stream slot and we get an average velocity of 4 m-persecond for $2 \mathrm{~m}$ in depth. Thus the wheel is moving as fast as the water is moved. Our water wheel design should then from 3 to 6 times depth in diameter (e.g.: $3 \times 2=6 \mathrm{~m}$ to $6 \times 2=12 \mathrm{~m}$ ). Whenever possible we make the wheel as large as we can. However, there would be no improvement in performance if it were larger than 12 meter in diameter. So we can choose the diameter as 10 meter for our wheel as shown in Figure 7.

\subsubsection{How Many Blades in Our Wheel}

When we decided to design our wheel, we will "submerge the blades a distance equal to the head". Therefore, the spacing between the blades should be some convenient number times "PI" to get the working circumference.

In our example we have decided to work with the 10 meter diameter from the figures above, so the working circumference is 25.12 meter ( 10 minus a depth of $2=8$ meter $8 \times$ PI $=25.12$ meter) The space between the blades should be less than 2 meter, which in our example is the depth. So the number of blades is greater than 13 blades $(25.12 / 2=12.56)$ or rounded to 16 . So, we will build a wheel 10 meter in diameter with 16 blades or greater.

\subsubsection{How Fast Our Wheel Turn}

The most efficient energy transfer occurs when the wheel speed as the water speed. For undershot wheels. Eighty percent of 4.5 meter per second is 3.6 meter per second, which is the same as $216(3.6 \times 60=216)$ meter per minute. You divide this by the working circumference of 25.12 meter per revolution. This gives our answer of $8.6(216 / 25.12=8.6)$ revolutions per minute.

That is our best rotation speed. As we can see, it is rather slow. That is why we will need a speed increasing system so we need to use gear box for increasing the shaft generator speed.

\subsubsection{How Many KW Will Our Wheel Produce}

The power we will get depends on the width and the head difference. For our example, we have chosen 4 meter width and one meter head. For water velocity about $4.5 \mathrm{~m} / \mathrm{s}$ we have a flow rate of 36 cubic m/s. The parameter worthy of consideration is the efficiency. The efficiency determines the amount of electrical power that can be obtained from the existing potential energy of water. The losses associated with hydromatrix include:

1. losses due to civil work

2. losses due to penstock

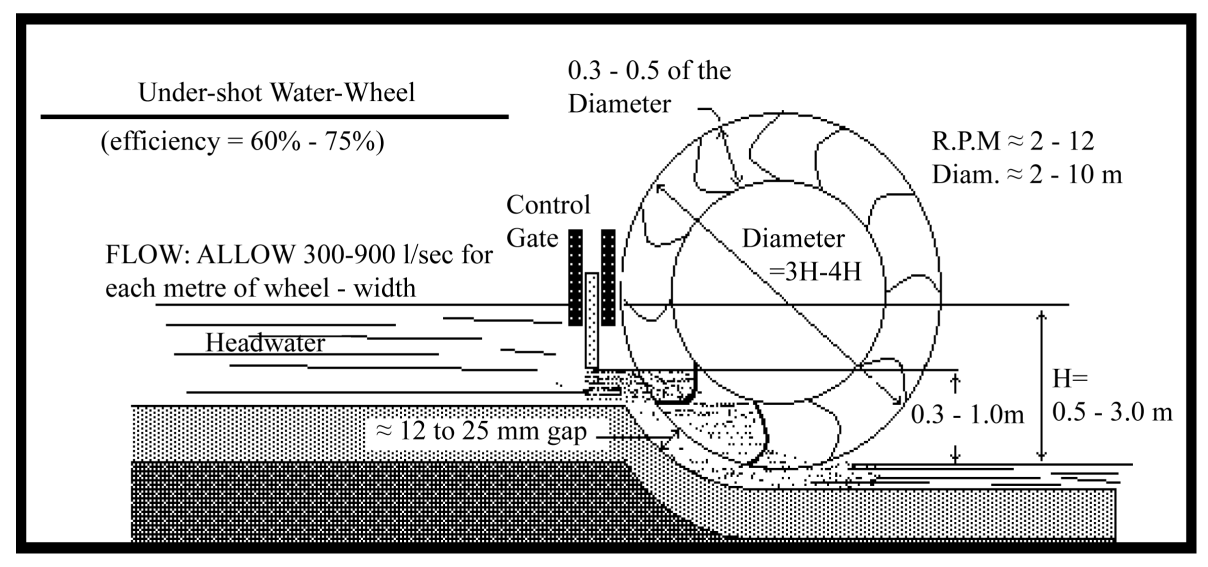

Figure 7. Under shot water wheel designing. 

3. tubing losses
4. generator losses
5. distribution losses
6. transformer losses (if the transformer is used)
7. losses due to the drive system

\section{$\mathbf{P}=\eta \rho \mathbf{g} \mathbf{H Q}$}

where, $\boldsymbol{\eta}=\boldsymbol{\eta}_{\text {civil work }} \times \boldsymbol{\eta}_{\text {slot friction }} \times \boldsymbol{\eta}_{\text {turbine }} \times \boldsymbol{\eta}_{\text {generator }} \times \boldsymbol{\eta}_{\text {drive system }} \times \boldsymbol{\eta}_{\text {line }} \times \boldsymbol{\eta}_{\text {transformer. }}$ According to [7] the practical ranges of these efficiencies are as stated below: $\eta_{\text {civil work }}=(1-$ (channel length $\times 0.002-0.005) / \mathrm{H}$ gross, $\eta_{\text {penstock }}$ $=0.90-0.95$ (it depends on the length), $\eta_{\text {turbine }}=0.60-0.85$ (it depends turbine type), $\eta_{\text {generator }}=0.80-0.95$ (it depends on the generator capacity), $\eta_{\text {drive system }}=0.97, \eta_{\text {line }}=0.90-0.98$ (it depends on the length and cross sectional area), $\eta_{\text {transformer }} \sim 0.98$. The losses due to civil work and penstock are calculated as head loss given as: Head loss $=\mathrm{H}_{\text {penstock }}+\mathrm{H}_{\text {valve }}+\mathrm{H}_{\text {bend }}$, Head loss $\sim$ (between 0.05 to 0.15 the $\mathrm{H}$ gross). The net power in KW, $\mathrm{P}_{\text {net }}$ $=\eta_{\text {turbine }} \times \eta_{\text {generator }} \times \eta_{\text {drive system }} \times \eta_{\text {line }} \times \eta_{\text {transformer }} \times 9.81 \times$ net head $\times$ flow rate. This yields the net theoretical electrical power that can be obtained from the site. This power can be determined for different values of flow. We should assume an overall efficiency of $35 \%$ according to [7] the power is equal to $\mathrm{p}=36 * 9.8 * 1 * 0.35=$ $123 \mathrm{KW} / \mathrm{h}$ for only one under shot water wheel.

\section{Hydro Power Plants}

Amongst renewable energy sources, hydroelectric power seems to be the most desirable for utilities and its economic feasibility has been successfully proven. Power stations with a capacity of up to $10 \mathrm{GW}$ have been built and it is estimated that there are economic resources for $3000 \mathrm{GW}$ world-wide, compared to 10,000 GW world primary energy consumption. In Europe, however, most hydroelectric potential has been realized, with Norway deriving $98 \%$ of its energy consumption from water power and the West German government concluding that there are no more sites available for exploitation. World-wide it is estimated that about $10 \%$ of resources have been realised, with most potential remaining in Africa and Asia. Present worlds total installed hydro power capacity is about 630,000 MW The annual power production world-wide is 2200 TWh (billion kilowatt hours), which means that the power plants are running at $40 \%$ of its rated power.

\subsection{Financial Considerations}

A 1.9 MW power plant (power from each hydro matrix), running at $90 \%$ of the time, will annually produce about $14.9 \mathrm{GWh}$ of electric power, at 15 cents/kWh that comes to almost 2.24 million $\$$ per year. The installation cost of a large scale hydroelectric plant varies widely, on the order of $\$ 1500-\$ 10,000$ per $\mathrm{kW}$.

Assuming a cost of $\$ 2500$ per $\mathrm{kW}$, total cost of 2.5 million $\$$ for a $1 \mathrm{MW}$ plant, the payback on investment would be a little over two years. Consider a remote location, fifty meters from an available electrical grid that has water available for a $\mathrm{S} \mathrm{kW}$ hydro-plant. The cost of installing a commercial power line also caries greatly, from $\$ 4000$ to $\$ 10,000$ per kilometer or more. In this instance a hydroelectric generating facility is very cost effective.

\subsection{Application}

Possible applications include, but are not limited to, the following:

1. Rivers-where damming of the river is impractical

2. Rivers or creeks in remote locations

3. Irrigation channels

4. Tidal channels and estuaries

5. Energy recovery from existing hydro schemes

The turbine is suitable for any anchored or tethered raft applications. As the paddle wheels are rotating in the vertical plane, rather than the horizontal, it is a simple matter to have the whole unit sitting on a small anchored raft, with a power cable running to shore. In this application it is irrelevant that the raft might twist or rise with the current or tide, unlike a horizontal plane paddle wheel. Alternatively, the turbine could be totally submerged (and less open to vandalism) with its energy transmission line running back up the anchoring cable. 


\section{Conclusions}

From the review of the engineering literature on hydropower converters for head differences below $2.5 \mathrm{~m}$ the following conclusions could be drawn.

- There are a number of established turbine technologies available. They do, however, suffer from economic disadvantages and from high ecological impacts. A modern development, the VLH turbine, addresses both economic and ecological deficits of traditional turbine technologies. Traditional technologies, such as water wheels, are employed again for sites below $200 \mathrm{~kW}$.

- Several novel technologies are under development and promise improved economic and ecological characteristics for hydropower with VLH differences.

\section{References}

[1] European Small Hydropower Association (ESHA) (2010) Energy Recovery in Existing Infrastructures with Small Hydropower Plants: Multipurpose Schemes-Overview and Examples.

[2] Linsley, R.K., Franzini, J.B. and Freyberg, D.L. (1992) Water Resources Engineering. McGraw-Hill Publications, New York.

[3] REN21 (2010) Renewables 2010 Global Status Report. 15-16.

[4] Krähenbühl, D., Zwyssig, C., Weser, H. and Kolar, J.W. (2009) Theoretical and Experimental Results of a Mesoscale Electric Power Generation System from Pressurized Gas Flow. Journal of Micromechanics and Microengineering, 19, Article ID: 094009. http://dx.doi.org/10.1088/0960-1317/19/9/094009

[5] Driscoll, H.J.R. (2008) Micro-Hydro Power in Dorset: A Re-Assessment of Potential Installed Capacity. Earth \& Environment, 3, 52-114.

[6] Lior, N. (2009) Energy Resources and Use: The Present (2008) Situation and Possible Sustainable Paths to the Future. Energy, 35, 2631-2638. http://dx.doi.org/10.1016/j.energy.2009.06.049

[7] Mueller, G. and Senior, J. (2007) The Hydrostatic Pressure Machine with Free Surface-A Novel Energy Converter for Very Low Head Differences. In: Zehntes Internationales Anwenderforum Kleinwasserkraftwerke 2007, Regensburg. 